\title{
Improved technique for toughness testing of shale rocks
}

\author{
Fabián J. Antinao Fuentealba, José L. Otegui*, Gustavo L. Bianchi \\ Innovation for Energy and Environment, Malvinas Institute, Faculty of Engineering, National University of La Plata, Argentina \\ National Scientific and Technical Research Council (CONICET), Argentina
}

\section{A R T I C L E I N F O}

\section{Keywords:}

Shale rocks

Toughness testing

Fracture fluids

Embrittlement

Fracture process zone

Uncertainty

\begin{abstract}
A B S T R A C T
Mode I fracture mechanics tests of mostly calcareous Vaca Muerta shale rocks were performed in a new experimental device. A hydraulic system allows the injection of pressurized fluids inside of cracks to generate applied $\mathrm{K}_{\mathrm{I}}$ and measure fracture toughness in room pressure and temperature conditions. Multi-notched 1.5" plugs were tested with different polar and non-polar fluids (waterbased fluids and organic solvents). Some samples were subject to previous saturation in order to activate multiple micro crack initiation via various embrittlement mechanisms. The methodology allows to test a large number of plug samples with low cost and times, and with a comparatively low uncertatinty and scatter of results with respect to other techniques. Results are discussed in terms of the two stress terms at the crack tip: Stress Intensity Factor $\left(\mathrm{K}_{\mathrm{I}}\right)$ and T-stress, and according to the Extended Maximum Tangencial Strain criterion (EMTSN). The variation of toughness in dry and saturated samples are discussed in terms of damage mechanisms, as well as in terms of the stochastic nature of toughness results in these rocks. The convenience of repeating these tests at reservoir pressure and temperature conditions is recognized.
\end{abstract}

\section{Introduction}

Shales are the most abundant of sedimentary rock types, and have become extremely important hydrocarbon resources. Oil and gas production from shales increased the quality and complexity of data required for evaluation and decision making, in order to reduce costs of drilling and completion, thus enhancing productivity. Improved understanding of shale reservoirs and extensive use of available data provide a driving force for new experimental methods and associated data analyses. Among mechanical properties of shale rocks, their resistance to cracking is of utmost importance.

In fracking wells for hydrocarbon exploitation, rock fracture is induced by pressurized fluid flowing through bores that cross the well wall into the rock. The bore acts as a sizeable notch from which the fracture propagates. Linear elastic fracture mechanics defines the fracture toughness $\mathrm{K}_{\mathrm{IC}}$ as the main material property defining the onset of fracture. Therefore, $\mathrm{K}_{\mathrm{IC}}$ influences hydraulic fracture propagation. However, there is some evidence that fracture toughness values obtained in laboratory conditions may not represent insitu values. $\mathrm{K}_{\mathrm{IC}}$ under reservoir conditions may be several times the values usually measured, prompting a need for more realistic test conditions [1-5].

Experiments in rocks have some technical details that must be considered to avoid erroneous results and/or high uncertainty. There are techniques and procedures for the initial conditions of rock samples with respect to temperature, humidity, absorbed or released fluids and process time, fluid distribution, and heterogeneity [6-8]. Another effect of temperature is the volumetric

\footnotetext{
* Corresponding author at: Innovation for Energy and Environment, Malvinas Institute, Faculty of Engineering, National University of La Plata, Argentina.

E-mail address: jotegui@fi.mdp.edu.ar (J.L. Otegui).
} 


\section{Nomenclature}

a Crack length

$\alpha \quad$ Crack length-diameter ratio

$\alpha^{*} \quad$ Critical crack length ratio

B Biaxiality ratio

D Specimen diameter

EMTSN Extended Maximum Tangencial Strain Criterion

$\varepsilon_{\theta \theta} \quad$ Tangential strain in polar coordinate

FPZ Fracture process zone

$F(\alpha) \quad$ dimensionless geometric factor
$K_{I C} \quad$ Critical fracture toughness

$K_{\text {If }} \quad$ Apparent fracture toughness

MMTS Modified maximum tangential stress criterion

SED Minimum strain energy density criterion

$\nu \quad$ Poisson's ratio

$r_{c} \quad$ Critical radius or FPZ length

$\sigma_{0} \quad$ Material yield strength

$\sigma \quad$ Nominal stress away from the crack tip

T T-stress parameter

$\mathrm{T}^{*} \quad$ Normalized T-stress parameter

expansion of the mineral phases with different expansion coefficients, that would likely induce termal nucleation of micro cracks in uncertain directions $[9,10]$. Wetting and drying cycles also affect the mechanical properties of rocks with high clay content [11-13]. Swelling and shrinkage are characteristic in argillaceous rocks in contact with aqueous solutions.

The Vaca Muerta formation presents a high degree of heterogeneity in various properties $[14,15]$. The thermomechanical history of rock constituents influences the design of experiments, hampers the selection of a representative volume to define properties and contributes to experimental uncertainties that are difficult to elliminate. The circumstances in which the outcrops samples are found are disparate; the degree of weathering in rock surfaces due to atmospheric agents can be highly variable.

Different approaches describe the characteristic non-linearity in cracked rocks and in quasi-brittle materials [16,17]. Smith et al. [18] and Ayatollahi et al. [19] considered the first non-singular parameter of the William's series near the crack tip [20]. Considering Hook's law, pure mode I opening and $\theta=0^{\circ}$, the mathematical description of strain $\left(\varepsilon_{\theta \theta}\right)$ in polar coordinates (Fig. 1) is [21]:

$$
\varepsilon_{\theta \theta}=\beta \frac{K_{I}}{\sqrt{2 \pi r}}-\gamma T+O(r)^{1 / 2}
$$

where $\beta=\frac{1-\nu}{E}, \gamma=\frac{\nu}{E}$ for plane stress, and $\beta=\frac{(1-2 v)(1+\nu)}{E}, \gamma=\frac{\nu(1+\nu)}{E}$ for plane strain. For a certain position (r, $\left.\theta\right)$ the stress field is governed by two parameters: Stress intensity factor $\left(\mathrm{K}_{\mathrm{I}}\right.$ and the first non-singular term $\mathrm{T}$ (or T-stress), which depend on sample geometry and load configuration. Is has been shown that $\mathrm{K}_{\mathrm{I}}$ and $\mathrm{T}$ are also dependent on the confining pressure [5,23-25]. The term $O(r)^{1 / 2}$ represents other terms of the serie expansion.

There is coalescence of micro cracks when a combination of $\mathrm{K}_{\mathrm{I}}$ and $\mathrm{T}$ achieve a critical state, for which the surrounding material is no longer able to sustain the load, and a micro-mechanical damage area is formed, with considerable energy dissipation [26].

The 'local' approach of Williams equations tries to justify the deviations in stress and strain fields near the crack tip from those predicted by LEFM. The common factor of these models is the hypothesis concerning FPZ size [17,27]. Chao et al. [28] defines the dependence of toughness with load and geometry 'constraint effect'. A sample with high constraint has a positive $\mathrm{T}$ [29]. Values of $\mathrm{K}_{\mathrm{IC}}$ in different samples of the same material depend on each particular T value. DCB (Double Cantilever Beam) and SENT (Single Edge Notch Tension) samples have high and low values of T, respectively. $\mathrm{K}_{\mathrm{IC}}$ values calculated as recommended by the ASTM E399 standard are not constant [29].

There are several crack propagation criteria that include the contribution of T-stress or other non-singular parameters. For example the minimum strain energy density (SED) [30], the modified maximum tangential stress (MMTS) [31] and the extended maximum tangencial strain (EMTSN) [21]. They consider the contribution of T-stress or $\mathrm{A}_{3}$ (third non-singular term). These criteria have been shown to explain the differences betwen the one- and two- parameter approaches to rock fracture toughness. Furthermore, from statistical models applied to fracture toughness results, it is possible to predict the toughness in others geometric and load

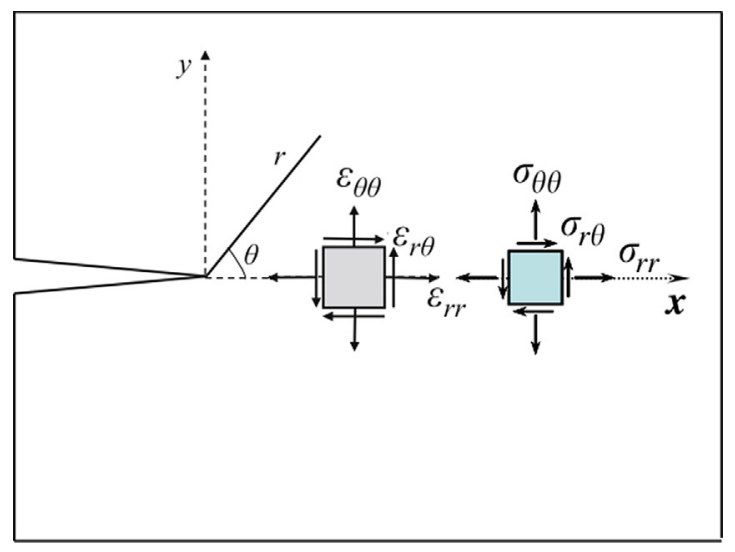

Fig. 1. Reference system for crack tip stress field [21,22]. 
conditions [32,33].

The extraction and machining of rocks from deposits favors the forming of cylindrical samples. So, several methods have been especially developed to measure rock fracture parameters: bending of a notched cylinder [34], three or four point bending of a semicircular disc with a central notch (SCB) [35,36], and the Brazilian disc (CCNBD) [37]. These tests are adaptations of methodologies initially developed to study the tensile behavior of isotropic [38] and anisotropic [39-41] materials. The mechanical stresses to the cracked sample are transmitted from a bending moment applied to the specimen. It is difficult to transfer tensile forces to the samples when testing brittle materials.

The main purpose of this article is to present how a novel testing methodology has been applied to toughness measurements of shale rocks at room pressure, with high reliability and low cost. Toughness values are measured from experiments performed on a device in which, using a hydraulic loading scheme, an "injection" fluid transmits the load into pre-cracked cylindrical samples. In this way, the fluid pressure induces stresses on the faces of the notch or initial crack, that causes mode I opening of the crack. At the same time, contact with active chemicals in the fluid allow assessing interaction between fluid chemistry and crack initiation. Different fluids have been tested to analyze their influence on toughness of dry and saturated samples.

Unlike all other toughness testing methods up to date, this procedure allows for close contact between the material at the crack tip and the fracturing fluid during the whole test. Thus, the method can be used to test and understand diffusive phenomena, which may lead to toughness reductions via Stress Corrosion Cracking (SCC) [42-44]. The procedure has been applied to accurately identify the effect of different active agents in the fracking fluid upon fracture toughness of carbonatic shale rocks from the Vaca Muerta oil \& gas reservoirs [45].

\section{Experimental methods}

Rock samples were taken from the outcrops in the 'Sierra de la Vaca Muerta', in South-Central Neuquen basin in Argentina, near the locality 'Los Catutos', Fig. 2. Rocks were extracted according to their lamination directions. Difraction Ray X results (DRX) show that rocks have mainly high contents of calcite and quartz (Table 1). Moreover, samples contain percentages lower than $1 \%$ of smectite and feldespar.

Samples were cut with diamond saw in $30 \mathrm{~cm}$ side cubic 'blocks'. Then $38 \mathrm{~mm}\left(1.5^{\prime \prime}\right)$ diameter, $40-60 \mathrm{~mm}$ long plugs were machined out with a diamond core drill bit (Fig. 3). Each notch was machined in two stages: the first $6 \mathrm{~mm}$ with a $1 \mathrm{~mm}$ thick saw, and then with a $0.35 \mathrm{~mm}$ diameter diamond wire until final length (between $6 \mathrm{~mm}$ and $21 \mathrm{~mm}$ ). Crack planes were always perpendicular to rock lamination (Fig. 3B)

The use of a V-notch or chevron notch is a common method for creating the pre-crack for rock materials. The method has been shown to aid in maintaining the crack path within a predefined plane, particularly in rocks and other brittle materials [46]. For mechanically transmitted loads, this is important to reduce errors in the calculation of crack driving forces. However, machining the notches is difficult, adding machining time and cost to each experimental point. For fluid-driven crack propagation, the accuracy of crack growth plane is not so relevant, so up to now we have always used a straight notch for crack initiation.

The plugs were dried in oven at $45 \pm 2{ }^{\circ} \mathrm{C}$ for $24 \mathrm{~h}$ to remove water until negligible weight loss and stored in a dryer. Typically, the plugs lost $1.5 \mathrm{wt} \%$ with respect to their 'wet' condition. In subsequent saturation trials, fluid gain was larger than $2.5 \%$ with respect to the previous dry weight. Sample plugs exposed to room humidity and temperature $\left(20-25{ }^{\circ} \mathrm{C}, 30-50 \%\right)$ took around $1 \%$ wt $\%$ moisture.

To ensure comparable results for different conditions, the samples were grouped in blocks, each assigned a serial number as listed in Table 1. In this way, random errors due to compositional and mineralogical differences within each block were minimized. As an example, rock set 10 (Table 2) has 46 samples, which form a set with a minimum compositional and mineralogical variability. 13
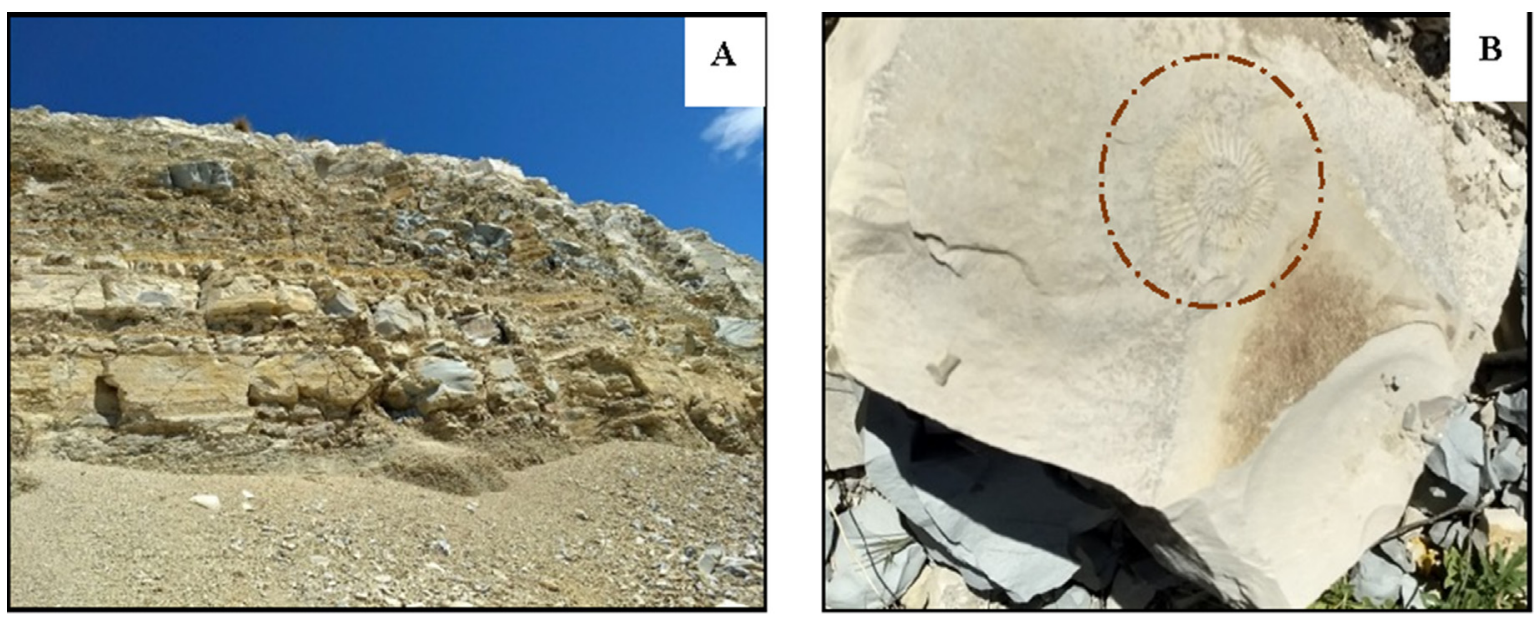

Fig. 2. (A) Overview of Vaca Muerta outcrop. (B) Detail of sample, note fossil traces. 
Table 1

Mineralogic composition.

\begin{tabular}{ll}
\hline Mineral & Percentage \\
\hline Calcite & 89 \\
Quartz & 9 \\
Plagioclase & 1 \\
Clay (smectite) + Feldespar & $<1$ \\
\hline
\end{tabular}
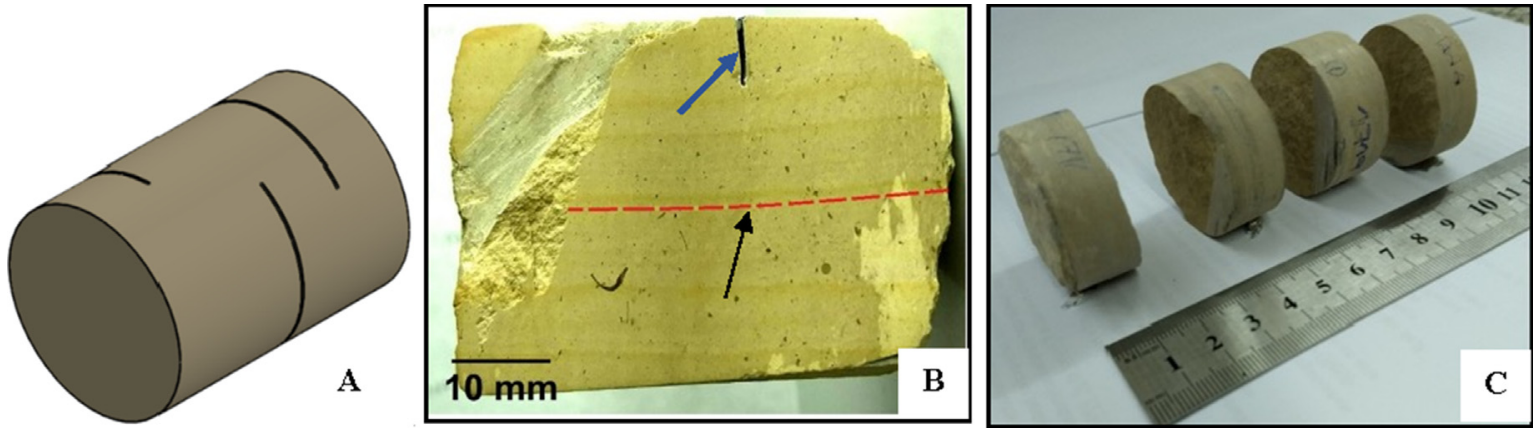

Fig. 3. (A) 'Plug' test sample with multipe notches. (B) Relative directions between rock lamintation (black arrow) and notch (blue arrow). (C) Test sample after three $\mathrm{K}_{\mathrm{If}}$ tests. (For interpretation of the references to colour in this figure legend, the reader is referred to the web version of this article.)

Table 2

Statistical data for all fracture tougness results in our tests.

\begin{tabular}{llllll}
\hline Rock Set & Internal Serial Number & Standard Deviation of $\mathrm{K}_{\mathrm{If}}\left(\mathrm{MPa} \cdot \mathrm{m}^{1 / 2}\right)$ & $\mathrm{Mean}_{\mathrm{If}}\left(\mathrm{MPa} \cdot \mathrm{m}^{1 / 2}\right)$ & Number of tests & Condition \\
\hline 01 & S300 & 0.15 & 0.63 & 9 & Environmental humidity (EH) \\
02 & S400 & 0.22 & 0.75 & 9 & Environmental humidity (EH) \\
03 & S500 & 0.10 & 0.59 & 9 & Environmental humidity (EH) \\
04 & S1600A & 0.09 & 0.54 & 19 & Environmental humidity (EH) \\
05 & S1600B & 0.09 & 0.64 & 9 & Environmental humidity (EH) \\
06 & S1600C & 0.13 & 0.85 & 11 & Environmental humidity (EH) \\
07 & S1400 & 0.08 & 0.75 & 7 & E.H (Previously dried) \\
08 & S1700 & 0.04 & 0.53 & Dry (D) \\
09 & S2000 & 0.15 & 0.82 & Dry (D) \\
10 & S2200 & 0.09 & 0.65 & 12 & Dry (D) \\
10 & S2200 & 0.10 & 0.20 & 9 & Destilled Water (DW) \\
10 & S2200 & 0.10 & 0.51 & 11 & 2 API \\
10 & S2200 & 0.05 & 0.57 & 10 & Isopropyl alcohol (I) \\
10 & S2200 & 0.16 & 0.54 & 10 & Kerosene (K) \\
11 & S2400 & 0.08 & 0.66 & 11 & Dry (D) \\
12 & S2400 & 0.04 & $0.13-1.2$ & 35 & Dry (D) \\
13 & SA-TW & - & & 200 & Dry (D) \\
TOTAL & & & &
\end{tabular}

$* \mathrm{~K}_{\mathrm{If}}$ range for notch depth ratios $0.1<\mathrm{a} / \mathrm{D}<0.55$.

rock sets were tested (Table 2). Full data is supplied as supplementary data.

The first six sets of shale rock were not saturated and were only affected by room humidity (sets 1-6, Table 2). These samples are considered under uncontrolled preparation conditions, subjected to environmental humidity (EH) while stored. Rock sets 8-12 were saturated and are considered under controlled preparation conditions. Rock set 7 was dried and then partially saturated at room humidity. The following fluids were selected to analyze the effect of saturation on fracture toughness for rock set 10 (Table 2 ).

- Fluid 2-API: saline solution with wt $2 \%$ potassium chloride. This fluid is widely used in oil and gas production operations, to avoid clay swelling $[13,47]$.

- Distilled water: to maximize rock deterioration from chemical reaction on Si-O bonds and clay swelling due to presence of smectite (see Table 1) [48-50]

- Isopropyl alcohol, kerosene: organic compounds expected a priori not to cause chemical reactions. However, Grgic et al. [51] and Jeong et al. [52] suggest secondary reaction of ethanol with $\mathrm{Si}=\mathrm{O}$ bonds.

- Non-saturated condition: Dried samples at $45 \pm 2{ }^{\circ} \mathrm{C}, 24 \mathrm{hs}$. 
For these rock sets, the (a/D) notch ratio was $0.15<\mathrm{a} / \mathrm{D}<0.25$. To further study the effect of crack length on fracture toughness, a group of samples was tested with a larger variation of notch ratios: $0.1<\mathrm{a} / \mathrm{D}<0.55$ (rock set 13 , Table 2 ).

The mode I fracture tests were performed in a new experimental device that allows the injection of a fluid inside of the crack tip, pressured by a hydraulic system (Fig. 4A). The fluid-driven force is transmitted to the crack surfaces through a pressure intensifier (Fig. 4A). A sample-seal packaging allows the hydraulic isolation inside the pressure chamber (Fig. 4B, C). Pressurization of each sample is accomplished in a $5 \mathrm{~mm}$ long annulus around the plug perimeter as shown in Fig. 4D. This contact area adds up to the initial notch area for fluid-rock interaction during $\mathrm{K}_{\mathrm{I}}$ testing.

The fluids used to generate applied $\mathrm{K}_{\mathrm{I}}$ are the same as those used in the saturation of the sample. The methodology allows to quantify a large number of samples with low cost and times, and, as we will see, with a comparatively low dispersion of results with respect to other techniques.

\section{Experimental results}

\subsection{Fracture mechanics assessment}

Aliha et al. [21] applied the EMTSN criterion, considering the strain state at the crack tip (Fig. 1) for a mode I crack opening. When the material reaches a maximum critical strain state, ignoring high order terms, the critical parameters become:

$$
\varepsilon_{\theta \theta_{c}} \sqrt{2 \pi r_{c}}=\beta K_{I f}-\gamma T_{c} \sqrt{2 \pi r_{c}}
$$

The left term is a material constant. The critical radius $r_{c}$, is related to FPZ size. The magnitude $\mathrm{T}_{\mathrm{c}}$ is the parameter $\mathrm{T}$ at the time of fracture and $\mathrm{K}_{\mathrm{If}}$ is the apparent fracture toughness measured during the tests:

$$
K_{I f}=\sigma \sqrt{\pi a} F(\alpha, \delta, . .)
$$

$F(\alpha, \delta, \cdots)$ is a dimensionless geometric factor, $a$ is crack depth, $\alpha$ is the length ratio $\frac{a}{D}, D$ is a characteristic dimension, $\delta$ is another dimensionless geometric variable, and $\sigma$ is the nominal stress away from the crack tip. If $\mathrm{K}_{\mathrm{If}}$ is not a material property, then:
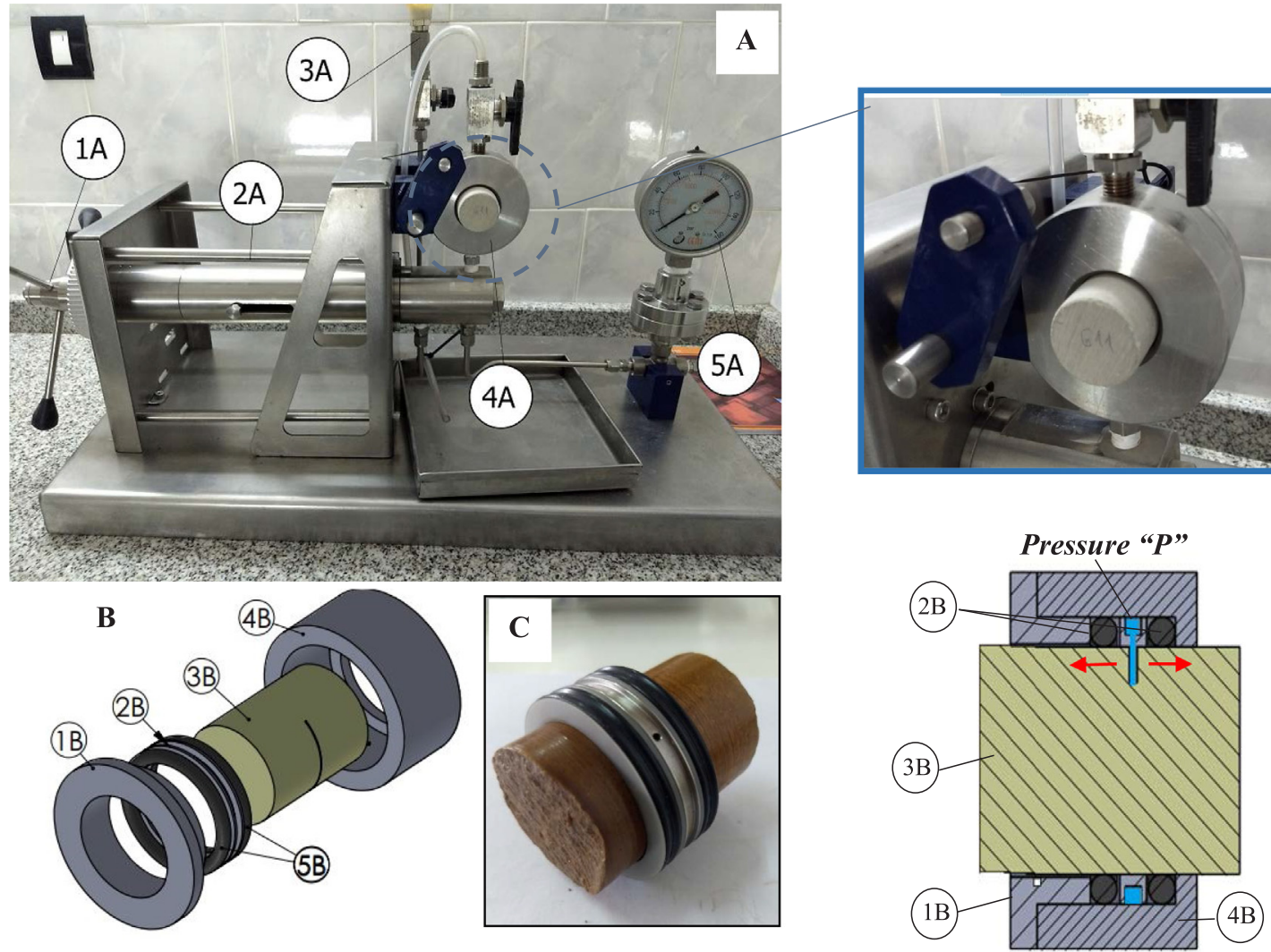

Fig. 4. (A) Hydraulic fracture test device: 1A Handle, 2A Pressure intensifier, 3A Fracture fluid inlet valve, 4A Pressure chamber, 5A Manometer. (B, C) Detail of pressure chamber and plug-seals packaging: 1B closing nut, 2B separator ring, 3B rock specimen, 4B chamber body, 5B hydraulic seals. (D) Sectional view of specimen under test, red arrows indicate the crack opening. (For interpretation of the references to colour in this figure legend, the reader is referred to the web version of this article.) 


$$
K_{I f}=K_{I f}(\sigma, \alpha, \cdots)
$$

If we define $\mathrm{K}_{\mathrm{IC}}$ as the measured toughness for $\mathrm{T}_{\mathrm{C}}=0$, then from Eq. (3):

$$
K_{I C}=\frac{\varepsilon_{\theta \theta_{c}} \sqrt{2 \pi r_{c}}}{\beta}
$$

Combining these equations:

$$
K_{I C}=K_{I f}(\sigma, \alpha, \delta, \cdots)-\frac{\gamma}{\beta} T_{c} \sqrt{2 \pi r_{c}}
$$

It is known that $r_{c}$ values depend upon the material [53] and sample size [27]. Quasi-brittle materials such as rocks have near-zero plastic deformation but a relatively large size of the FPZ. Due to microcracking in this FPZ, during the loading process these rocks present a loss of stiffness and mechanical strength [54]. A new parameter must be taken into account for the characterization of the non-linearity. Aliha et al. [21] and Ayatollahi et al. [27] propose expressions to calculate $r_{c}$ for rocks. Literature shows values of $T^{*}=\frac{T}{\sigma_{r e f}}$, non-dimensional with respect to a reference stress $\sigma_{r e f}[25,55,56]$ and as a function of sample diemensions. If $K_{I f}$ is calculated as a function of this same reference stress, then from Eqs. (5) and (6), the relation $K_{r}=\frac{K_{I C}}{K_{I f}}$ is obtained:

$$
K_{r}=1-C_{1} \frac{T^{*}(\alpha, \delta, \cdots)}{K_{I f}(\alpha, \delta \cdots)}, \quad C_{1}=\frac{\gamma \sqrt{2 \pi r_{c}} \sigma_{r e f}}{\beta}
$$

Eq. (7) can be rewritten as eq. (8), with $B$ the biaxiality ratio, and $\alpha^{*}$ the critical crack length ratio [21] (plane strain):

$$
K_{r}=1-\frac{\nu}{1-2 \nu} B \alpha^{*} ; \quad B=\frac{T \sqrt{\pi a}}{K_{I}}, \quad \alpha^{*}=\sqrt{\frac{2 r_{c}}{a}}
$$

Note that this definition does not allow to compare the values of $T^{*}$ for different geometries.

Accord to early analysis, the non-linearity of the fracture mechanics behavior from EMTSN criterion depends on:

- Consideration of plane state of stress or strain.

- The critical radius or size of the fracture process zone. This is a physical intrinsic parameter.

- The variation of T with notch size. This is a geometric parameter.

- The apparent stress intensity factor and its dependence with notch ratio (a/D)

Apparent fracture toughness $\left(K_{I f}\right)$ from our experiments were calculated as per Eq. (4), for $\sigma=P$, notch pressure, $F(\alpha, \delta \cdots)=F\left(\alpha=\frac{a}{D}\right)$, with $\mathrm{D}=1.5^{\prime \prime}$. Using superposition in LEFM [57]:

$K_{I C}=P \sqrt{\pi a} F(\alpha)$

The F(a/D) coefficient is $[57,58]$

$$
F\left(\frac{a}{D}\right)=0.926-1.77\left(\frac{a}{D}\right)+26.421\left(\frac{a}{D}\right)^{2}-78.481\left(\frac{a}{D}\right)^{3}+87.911\left(\frac{a}{D}\right)^{4}
$$

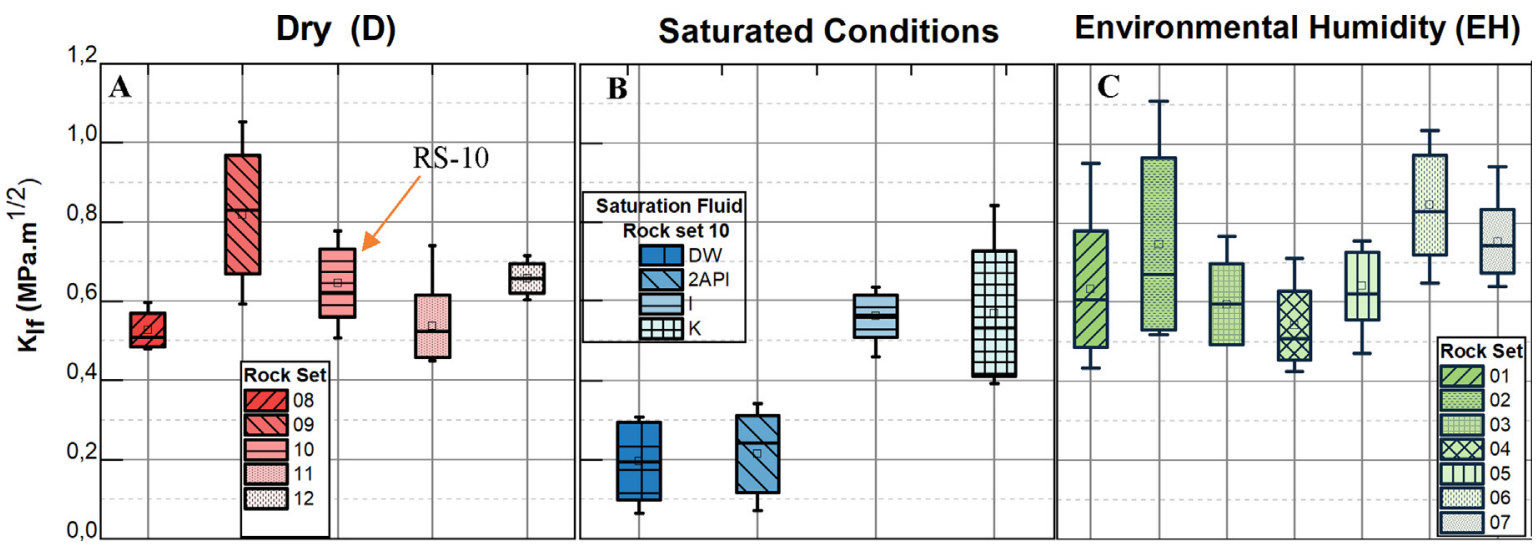

Fig. 5. Box plots of fracture toughness results of VM shale samples with different preconditioning (Table 2). Whiskers show the maximum and minimum values for each data set, squares are mean values, and box limits represent \pm 1SD (standard deviation). 


\subsection{Fracture toughness results}

Box plots in Fig. 5(A-C) show fracture toughness results of Vaca Muerta shale notched-plug samples subjected to different saturation and fracturing fluids. Note how samples from rock set 10 show a marked decrease in toughness when saturated in both water-based and organic-based solvents (DW, 2API, K and I inner Fig. 5B) with respect to the 'dry' condition (arrow in Fig. 5A).

Fig. 5 shows fracture toughness vs. standard deviation for these tests (crosses), when compared with average toughness and deviations reported in the literature, for samples of various geometries (BD: Brazilian Disk, CB: Chevron Bending, CCNBD: Cracked Chevron Notched Brazilian Disk, CNBB: Chevron Notched Bend Beam, SCCBD: Straight Center Cracked Brazilian Disk, SECRBB: Single Edge Cracked Round Bar Bend, SENB: Single Edge Notched Beam). Table 2 summarizes the global test results, including mean values and standard deviation of data.

Despite the relatively high scatter for rock sets 01 and 02 (Fig. 6), tested in uncontrolled room humidity conditions (black arrows), it is worth noting that experimental scatter is notably smaller in most our tests with controlled conditions than those of all other tests reported $[3,32,36,59,60]$.

Fig. 7(A-C) shows the variation of toughness with (dimensionless) notch depth, for each condition of saturation and preparation. Twelve sets of data are presented in dry, partially saturated (environmental humidity) and fully saturated conditions. The lines show tendencies.

Fig. 8A shows the crack length effect in rock set 13 (blue dots); included are also results for all rock sets tested in dry condition (grey dots, Fig. 8A and B). Fig. 8B shows recent literature [57] test results in high quartz synthetic rock with the same load-geometry condition, which show a similar trend. This figure also shows the effect of crack tip sharpness (defined by notch radius " $r$ ")

\subsection{Estimation of T-stress}

An estimation of T-stress parameter was carried out considering the EMTSN criterion, as discussed in section 3 . The analysis for the small diameter, notched plug samples considers plane strain, $T^{*}=T^{*}(\alpha)\left(T^{*}=\frac{T c}{P}, P=\right.$ notch pressure, $\left.\alpha=a / D\right), v=0.18$, and that $K_{I f}$ depends on a/D. From Eq. (8), Eq. (11) allows to estimate $T^{*}$-stress and T-stress parameters if $K_{I C}, K_{I f}$ and $r_{c}$ are known:

$$
T^{*}\left(\frac{a}{D}\right)=\left(1-\frac{K_{I C}}{K_{I f}}\right) \frac{1-2 v}{\nu} \sqrt{\frac{D \alpha}{2 r_{c}}} F(\alpha) ; T^{*}\left(\frac{a}{D}\right)=\frac{T}{P}
$$

Chavez et al. [61] made fracture toughness tests from SCB specimens with the same rock composition. Specimen geometry and results are shown in Table 3; geometry and load condition are such that $\mathrm{T}^{*}$-stress $=0$ [55]. Thus, Table 3 shows true fracture toughness; mean value is $K_{I C}=0.58 \mathrm{MPa} \mathrm{m}^{0.5}$, with a standard deviation $\sigma_{K_{I C}}=0.38 \mathrm{MPa} \mathrm{m}^{0.5}$. The relation $K_{r}=\frac{K_{I C}}{K_{I f}}$ can be calculated from these values and those for rock set 13. $K_{r}$ is shown in Fig. 8C, as a function of notch ratio a/D.

From Eq. (12), the $r_{c}$ values can be estimated according to LEFM [36], if toughness and tensile strength are known:

$$
r_{c}=\frac{1}{2 \pi}\left(\frac{K_{I C}}{\sigma_{t}}\right)^{2}
$$

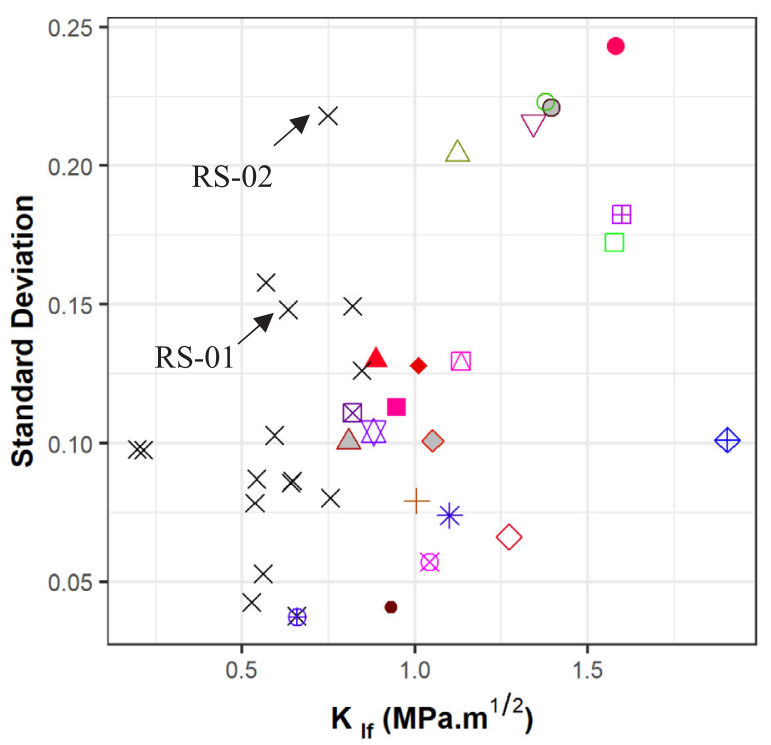

\footnotetext{
$\square$ BD- Limestone A - Guo et al.(1993) $\boxplus$ CB- Sandstone B- Stöckhert (2015) BD- Limestone B -Guo et al.(1993) 叉 CB-Sandstone B - Backers (2004) $\triangle$ BD- Marble A- Guo et al.(1993) $\triangle$ CCNBD- Marble- Aliha et al.(2014) + BD- Marble B- Guo et al.(1993) $\square$ CCNBD- Marble- Alina et al.(2018) $\checkmark$ CB- Limestone- Backers (2004) CNBB- Marble- Aliha et al. (2018) $\diamond \mathrm{CB}$ - Limestone- Stöckhert (2015) $\quad$ S SCCBD- Marble- Aliha et al.(2018) $\nabla$ CB- Marble- Aliha et al.(2018) SECRBB Marble- -Aliha et al.(2018) $\triangle \mathrm{CB}$ - Marble- Stöckhert (2015) $\triangle$ SENB- Limestone A- Schimidt (1977) * CB-Marble A- Backers (2004) - SENB- Limestone B- Schimidt (1977) $\diamond \mathrm{CB}$ - Marble B- Backers (2004) $\bigcirc$ SENB- Marble- Aliha et al.(2018) $\oplus \mathrm{CB}$ - Sandstone A- Backers (2004) $\times$ VM Shale Plug X CB- Sandstone A- Stockhert (2015)
}

Fig. 6. Fracture toughness vs. standard deviation for Vaca Muerta shale samples and others reported in the literature, according to sample geometry and rock type. 


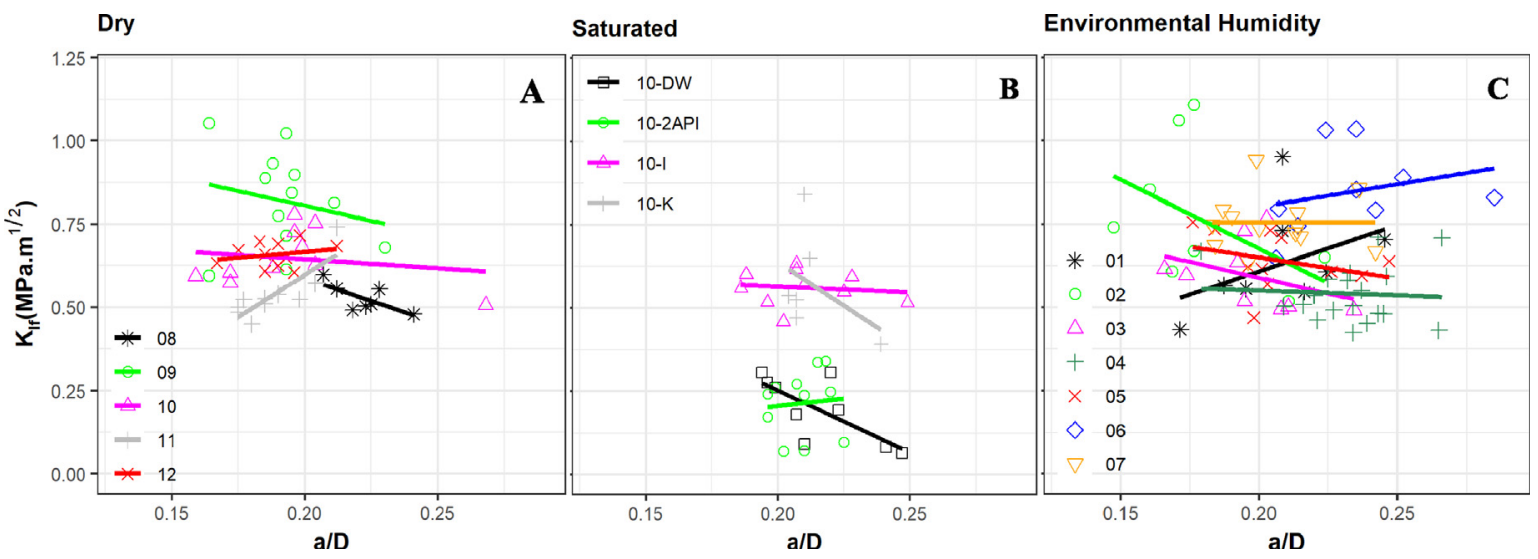

Fig. 7. Fracture toughness vs. notch depth. (A-C) From this study, differen t saturation conditions and rock sets.
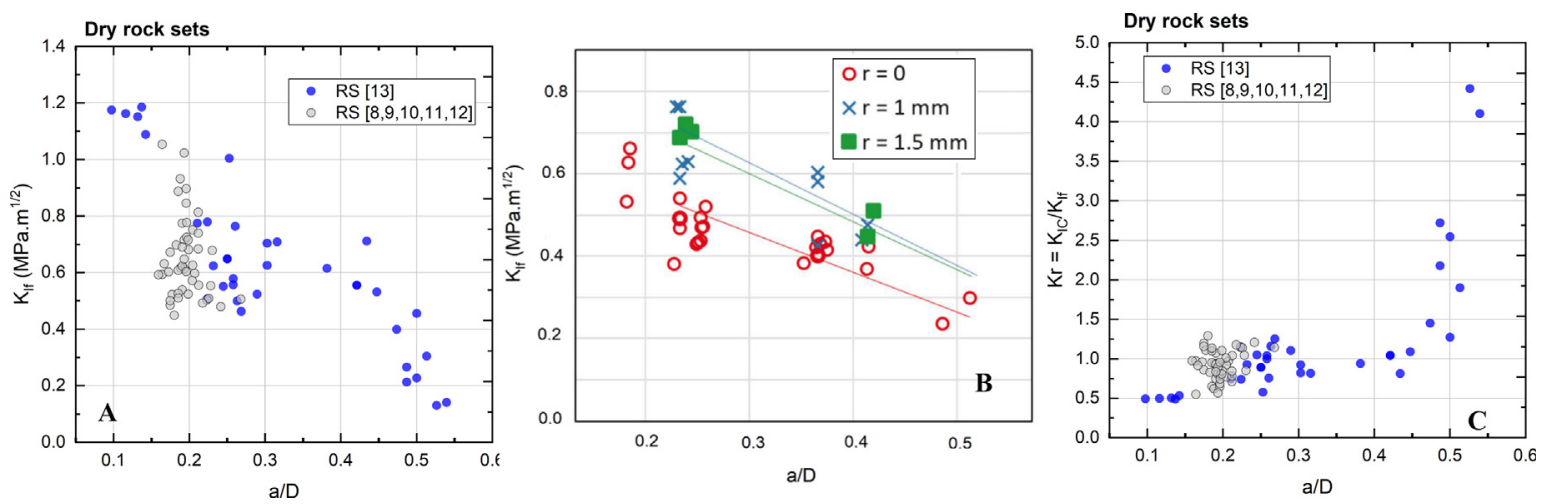

Fig. 8. (A) Rock set 13 and full rock sets in dry condition, as function of notch ratio a/D, (B) Literature data, same tre nd for a larger a/D range [57] and (C) Ratio $\mathrm{K}_{\mathrm{IC}} / \mathrm{K}_{\mathrm{If}}$ estimated from rock set 13 and fracture toughness test in SCB specimens, according to Chavez et al. [61]. Also it is show the same ratio for the others rock sets in dry condition.

Table 3

$\mathrm{K}_{\mathrm{IC}}$ test results from SCB samples with similar rock composition (calcareous rock from Vaca Muerta formation). Modifed after [61].

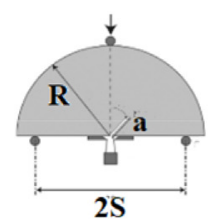

\begin{tabular}{|c|c|c|c|c|c|c|c|c|c|c|}
\hline Sample & $\begin{array}{c}\mathrm{B} \\
(\mathrm{mm})\end{array}$ & $\begin{array}{c}\mathrm{D} \\
(\mathrm{mm})\end{array}$ & $\begin{array}{c}\mathrm{R} \\
(\mathrm{mm})\end{array}$ & $\begin{array}{c}\mathrm{a} \\
(\mathrm{mm})\end{array}$ & $\begin{array}{c}\mathrm{S} \\
(\mathrm{mm})\end{array}$ & $\mathrm{a} / \mathrm{R}$ & $\mathrm{S} / \mathrm{R}$ & $\mathrm{Y}^{\prime}$ & $\begin{array}{c}\text { Max } \\
\text { Load } \\
(\mathrm{N})\end{array}$ & $\begin{array}{c}\mathrm{K}_{\mathrm{IC}} \\
\left(\mathrm{Mpa}^{1 / 2}\right)^{1}\end{array}$ \\
\hline LMD01 & 35 & 100 & 50 & 20 & 80 & 0.4 & 0.8 & 5.43 & 1946 & $\mathbf{0 . 7 5}$ \\
\hline LMD02 & 40 & 100 & 50 & 23 & 80 & 0.46 & 0.8 & 6.09 & 455 & $\mathbf{0 . 1 8}$ \\
\hline LMC03 & 41 & 100 & 50 & 20 & 80 & 0.4 & 0.8 & 5.43 & 3081 & $\mathbf{1 . 0 2}$ \\
\hline LMC03AC & 48 & 100 & 50 & 20 & 80 & 0.4 & 0.8 & 5.43 & 1327 & $\mathbf{0 . 3 7}$ \\
\hline
\end{tabular}

Measurements of tensile strength $\sigma_{t}$ for this rock composition (calcareous with perpendicular lamination planes) are shown in Table 4. Considering $6 \mathrm{MPa}<\sigma_{t}<8 \mathrm{MPa}$, the size of the fracture process zone is $r_{c} 1-2 \mathrm{~mm}$.

The resulting $\mathrm{T}^{*}$-stress and T-stress parameters are shown in Fig. 9(A, B). The relatively large scatter in $\mathrm{K}_{\mathrm{IC}}$ and $r_{c}$ results affect these values. Fig. 9C shows the theoretical linear relationship between $\mathrm{K}_{\mathrm{If}}$ and T-stress, according to Eq. (6).

Table 4

Tensile strength for calcareous rocks on Vaca Muerta Formation and other shale rocks around the world.

\begin{tabular}{lll}
\hline Reference & Tensile strength $\sigma_{t}[\mathrm{MPa}]$ & Rock type \\
\hline Massaro [62] & $6-8$ & Calcareous rock, Vaca Muerta Formation (outcrop) \\
Rybacki et al. [63] & $2-15$ & Differents shale rocks around the world \\
\hline
\end{tabular}



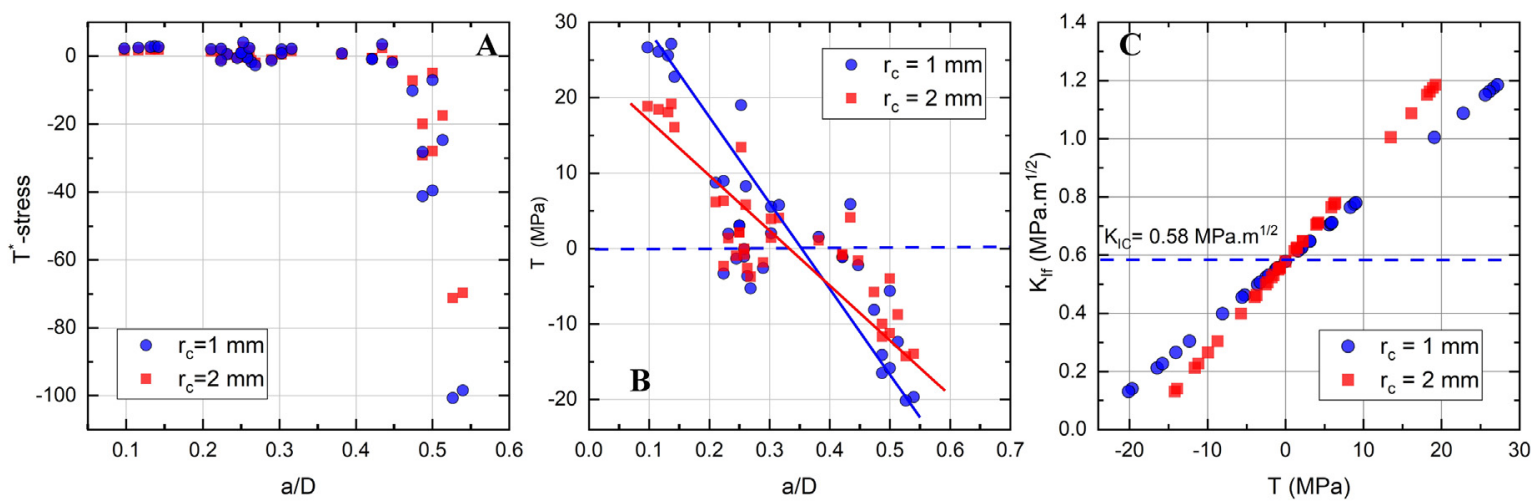

Fig. 9. T-stress parameters. (A) Dimensionless $T^{*}$ as function of notch ratio. (B) Absolute T-stress; the lines show tendencies. (C) Apparent fracture toughness as function of T-stress, according to EMTSN criterion.

\section{Discussion of results}

According to Section 3, the behavior of fracture mechanics test specimens is governed by more than one parameter (EMTSN criteria) and measuring toughness under the LEFM hypothesis leads to large scatter in the results. This is due to two different aspects:

- Geometrical and mechanical effect of $\mathrm{T}$ parameter. If $\mathrm{K}_{\mathrm{If}}$ is unchanged by the ratio $\alpha$, the measured toughness is the true one for the material when Tc $=0$. If Tc greater than 0 , toughness is overestimated, if $\mathrm{Tc}<0$, it is underestimated.

- Effect of intrinsic physical inhomogeneity, inherent to the genetics of the rock. In these circumstances, initiation and coalescence of micro cracks are of a stochastic nature. It is likely then that there are energy dissipation mechanisms not quantified by LEFM approaches.

In the next sections how these effects influence on experimental determination of fracture toughness is discussed.

\subsection{Effects of geometric and mechanical parameters on fracture toughness}

The effect of notch depth ratio was analyzed by Akbardoost [64], who considers the stress field at the crack dominated by two parameters $\left(\mathrm{K}_{\mathrm{I}}\right.$ and $\left.\mathrm{A}_{3}\right)$. He reported fracture toughness data performed on SENB graphite specimens. He used the MMTS criterion to justify the effect of crack length upon the magnitude $A_{3}$. He found differences of $1-12 \%$ (absolute values) for notch ratios $0.1<$ a/ $\mathrm{W}<0.7$. Our results (Fig. $8 \mathrm{~A}$ ) show that $\mathrm{K}_{\mathrm{If}}$ is very sensitive to the crack length ratio a/D. $\mathrm{K}_{\mathrm{If}}$ decreased more than $70 \%$ from the maximum values for short cracks $(\mathrm{a} / \mathrm{D}<0.25)$ to the lowest ones for long cracks $(\mathrm{a} / \mathrm{D}>0.45)$. It can be argued that these results are very influenced by large T-stress values for deep notches. For $0.15<\mathrm{a} / \mathrm{D}<25$, T-stress $\sim 0$, and so the measured toughness nears $\mathrm{K}_{\mathrm{IC}}$.

On the other hand, the notch used in our experiments $\left(0.4 \mathrm{~mm}\right.$ wide, blunt tip) is not very sharp. Fig. 8B shows $\mathrm{K}_{\mathrm{If}}$ values for a cementitious material, measured using the same sample and testing method as ours. Note the sensitivy with notch tip sharpness. The relative size of FPZ with respect to the notch tip radius could have an influence in our $\mathrm{K}_{\mathrm{I}}$ measurements. Some authors have shown that for sufficiently large FPZ, the notch geometry (sharp or rounded) do not have a notable effect on fracture toughness [65]. In our tests, notch radius is around $0.25 \mathrm{~mm}$, and the estimated FPZ is between 1 and $2 \mathrm{~mm}$ (about five times larger). This can be a potential source of overestimation of rock toughness, that would be less than $20 \%$ (see Fig. $8 \mathrm{~B}$ ). A small degree of overestimation of $\mathrm{K}_{\mathrm{IC}}$ in rocks is generally conservative, and in most cases, should not affect scatter in test results.

Figs. 6 and $7(\mathrm{~A}-\mathrm{C})$ show that scatter in most tests in plugs under controlled conditions is low for notch ratios $0.15<$ a/ $\mathrm{D}<0.25$. The most relevant reason is that the physical properties are relatively homogeneous in representative volumes. i.e., the inherent defects in the rocks do not cause remarkable differences in their fracture behavior. In addition, for notch ratios $0.15<$ a/ $\mathrm{D}<0.25$, six different rock sets tested in dry condition show similar tendencies regarding $\mathrm{K}_{\mathrm{If}}$ and $\mathrm{K}_{\mathrm{r}}$ (Fig. 8A, C).

If all dry samples were considered the same material, average toughness would be $0.64 \mathrm{MPa} \mathrm{m}^{1 / 2}$, with a scatter of $0.12 \mathrm{MPa} \mathrm{m}^{1 / 2}$ (Table 2). Samples were extracted from different outcrop positions (different quantity and type of defects, and disparate geological ages), and yet measured toughness has a relatively low scatter. Several authors have shown that scatter is related to stress concentration of specimen rigidity. For example, toughness tests on chevron- notched specimens (CCNBD) have been shown to have less scatter than straight-notched specimens $[32,33,66]$.This is because the chevron type notch favors high stresses concentration in the notch environment. This could be implemented in future experiments, to further improve scatter.

High specimen stiffness is regarded as an advantage of some geometries. This is true if the crack driving force is mechanically transmitted from the test rig into the specimen. $\mathrm{K}_{\mathrm{IC}}$ calculations in this case may require numerical modeling, and the determination of energy release rate with linear and nonlinear analyses differ in their results for low stiffness configurations [65]. In [67] CNSRB specimens are shown to yield lower scatter of testing results than the CB specimens. This is related to considerable compressive 
stresses in supports that may affect the accuracy of the fracture toughness measurements. A higher compressive load would consume energy due to compression-induced micro-damage [67]. A fluid-driven cracking method, as used in this research, allows to get rid of most of these uncertainties.

\subsection{How interaction between defects and fluids affects fracture toughness}

Fig. 5(A, B) shows that saturated rocks have lower fracture toughness than those tested in originally dry conditions. The decrease is dependent upon saturating fluid. Distilled water and saline solution of $\mathrm{KCl}$ caused a $70 \%$ decrease, the decrease with alcohol and kerosene was 25\%. Different authors have indirectly measured that the size of the FPZ is larger for samples saturated in certain aqueous solutions $[42,68]$. At the same time, the importance of FPZ $\left(r_{c}\right.$. $)$ is clear. Rock saturation causes mechanical damage within the rock sample, particulartly around the crack tip. This means that microcrack density increases, making their coalescence more likely at low loads.

The situation for $\mathrm{K}_{\mathrm{IC}}$ testing in metallic materials is somehow simpler: damage in the FPZ is mainly due to plasticity, which is, in turn, related to the material yield strength. In our cases, sensitivity to soaking and cracking fluids showcase the relevance of different damage mechanisms activated in the FPZ. There are physical and chemical effects (stress corrosion) and interaction between stresses and structure (pore pressure, capillary tension, clay swelling). Some mechanisms (stress corrosion, clay swelling) cause a localized damage, resulting in loss of mechanical stiffness. Other mechanisms modify the distribution of mechanical stresses at the crack tip (capillary tension, pore pressure).

No emphasis is placed in the literature upon the preparation of rock samples. Drying the rocks during preparation has been useful to remove water content, minimizing the effect of capillary tension. According to Schmitt et al. [69], capillarity effects are evident only in rocks with partial saturation, and are dependent on porosity level and pore sizes. The effect of stress corrosion is also minimal, as the amount of aqueous solution in the sample is negligible. Under atmospheric conditions, poral pressure is relatively constant, before and after the tests.

Drying temperature may have some effect on the rocks. Our samples are mainly composed by calcite and quartz; these minerals have differing and anisotropic coefficients of thermal expansion. Therefore, a change in temperature (from $20{ }^{\circ} \mathrm{C}$ to $45{ }^{\circ} \mathrm{C}$ ) could generate stress concentrations and, eventually, thermal nucleation of micro cracks.

It is very complex to ensure that rock samples have equal conditions at the crack tip, even with identical preparation. When load transfer into the FPZ begins, the inelastic response is different in each sample, as defects alter stress gradients in different manners. Hence homogeneity in physical properties (porosity, fluid content, chemical/mineralogical composition, presence of defects, grain size, etc.) is the main factor in the scatter of toughness results. Sample preparation and conditioning allows initial damage in the samples to be relatively the same. This would enable us to hypothetically isolate the effects of the mechanisms governing toughness in the presence of fluids.

These previous discussions illustrate that the FPZ contains a certain microcrack density, which controls measured toughness to a large extent. A key to further reduce scatter and uncertainty in fracture testing of shale rocks is therefore to ensure a similar initial microcrack density. References in the literatur [42,68,70] point to two basic techniques: ultrasound measurements and micro-tomography. Propagation speeds of mechanical waves are modified by matrix stiffness; detection thresholds may be the key in the applicability of tomography techniques.

\subsection{Experimental uncertainties still to be addressed in hydraulic fracture toughness tests}

Fluid-driven fracture tests in rocks have certain pecualiarities that must be recognized and understood. For notched samples in quasi-static conditions, pressure within the notch is homogeneous. So, the mode- 1 force line that transmits the load into the notch faces lie roughly in the middle of it, and it is stationary. However, in real testing conditions the fluid in contact with the notch faces tends to move through the rock pores, so there may be a temporal and spatial pressure variability. Therefore, the energy amount introduced by the hydraulic pressurization system is used to both, cause movement of fluid into the pore spaces and cause crack opening.

Experimentally, it has been seen that while the sample is loaded, the pressure shows a snap drop of $10-25 \%$ of its maximum value. Pressures introduced in the notches were of the order of 15-50 bar, reached in 40-60 s. Fluid losses through the system has been shown to be negligible in this range of time and pressure. At 20 bar maximum pressure, the hydraulic device loses less than $10 \%$ pressure in $40 \mathrm{~min}$. This is more than an order of magnitude smaller than the observed pressure drops. Therefore, losses due to fluid leakage from the pressure chamber are not the cause of the observed pressure drops.

Uncertainty in pressure values during the test takes relevance. The design of all toughness experiments through transmission of a hydraulic pressure should consider rock permeability. It is suggested to try 'waterproofing' techniques in the areas of fluid contact, so that the fluid-notch contact area is just close to the crack tip.

There is a final major source of uncertainty, which is directly translatable to how welll laboratory tests would eventually be able to predict the response of down-bore shale formations to hydraulic fracturing. This is the effect of both, temperature and triaxial compression. The first one can be readily replicated in the lab, since maximun temperatures do not exceed $90{ }^{\circ} \mathrm{C}$. Downhole pressure, on the other hand, can be as high as 350 Bar for Vaca Muerta shale oil \& gas reservoirs. This are orders of magnitude larger thah the rock yield strength and can arguably grossly modify not only conditions for mechanical constraint and T-stress, but the behaviour of the FPZ itself. That is, there may be issues not only with accuracy in measured toughness, but also with the similarity concept: at the microstructural level, the material must behave similarly in lab and real-life conditions. One way to prove how well these tests 
represent the behavoiur of shale formations would be testing notched plugs in triaxial compression. This is done by creating a differential pressure around the notches in plugs inserted in a pressurized chamber.

A finite element simulation of stress distribution and crack driving force under different hydraulic-driven testing conditions would aldo be useful to:

- Identify the effect of specimen geometry and loading conditions.

- Consider multi-parameter fracture mechanics models: KI, T-stress and A3.

- Contrast experimentally determined T-stress values.

- Determine which propagation model is the most suitable for the experimental results (MMTS, EMTSN, others).

- Verify the sensitivity of toughness to the notch depth ratio a/D.

- Identify the effect of confinement pressure (constraint) upon all the above issues.

\section{Conclusions}

Mode I fracture mechanics tests of Vaca Muerta shale rocks were performed in a new experimental device. A hydraulic system generates an applied $\mathrm{K}_{\mathrm{I}}$ and measures fracture toughness at room pressure and temperature. Multi-notched 1.5" plugs were tested with different polar and non-polar fluids (water-based fluids and organic solvents). Some samples were subject to previous saturation in order to activate multiple micro crack initiation via various embrittlement mechanisms. The advanteges of the methodology have been presented:

- testing a large number of plug samples with low cost and times.

- low uncertatinty and scatter of results when compared with conventional, mechanical loading techniques. This has been related to the relatively homogeneous physical properties in the small volumes tested.

Results were discussed in terms of the two stress terms at the crack tip: Stress Intensity Factor $\left(\mathrm{K}_{\mathrm{I}}\right)$ and T-stress, and according to the Extended Maximum Tangencial Strain Criterion (EMTSN). Apparent fracture toughness $\mathrm{K}_{\mathrm{If}}$ is very sensitive to notch ratio; influenced by large T-stress values for deep cracks. The variation of toughness in dry and saturated samples were discussed in terms of damage mechanisms, as well as in terms of the stochastic nature of toughness results in these rocks.

Saturated rocks have been shown to have lower fracture toughness than those tested in originally dry conditions. The decrease is dependent upon saturating fluid: $70 \%$ in distilled water and $\mathrm{KCl}$ solution, $25 \%$ with alcohol and kerosene. Rock saturation causes mechanical damage in the Fracture Process Zone (FPZ) around the crack tip. As microcrack density increases, their coalescence at low loads is more likely. Physical and chemical effects (stress corrosion) and interaction between stresses and structure (poral pressure, capillary tension, clay swelling) have been discussed. Some mechanisms (stress corrosion, clay swelling) cause a localized damage, resulting in loss of mechanical stiffness. Other mechanisms modify the distribution of mechanical stresses at the crack tip (capillary tension, poral pressure).

To further reduce scatter and uncertainty in fracture testing of shale rocks, it is proposed to previously define initial microcrack density within the FPZ by means of ultrasound measurements and micro-tomography. It is also suggested to 'waterproof' areas of fluid contact, so that the fluid-notch contact area is just close to the crack tip.

A final major source of uncertainty is how well laboratory tests predict the response of down-bore shale formations to hydraulic fracturing. The convenience of repeating these tests at reservoir pressure and temperature conditions is recognized. In order to consider the effect of downhole pressure (as high as 350 Bar for Vaca Muerta) and insure similarity of damage mechanisms at the microstructural level, notched plugs will be tested in triaxial compression.

\section{Acknowledgements}

This research was partly funded by CONICET (Consejo Nacional de Investigaciones Científicas y Técnicas, Argentina). Authors thank Ricardo Ramos from SOLAER S.A. for motivation and funding for this research. Thanks are also given to Aníbal Márquez and Juan C. Belmonte from INTEMA (UNMdP-CONICET) for the design of experimental devices and early testing, and to Ariel Sánchez Camus from TECTIONS S.A. for helpful discussions and encouragement.

\section{Appendix A. Supplementary material}

Supplementary data to this article can be found online at https://doi.org/10.1016/j.engfracmech.2020.107182.

\section{References}

[1] Al-Shayea NA, Khan K, Abduljauwad SN. Effects of confining pressure and temperature on mixed-mode (I-II) fracture toughness of a limestone rock. Int J Rock Mech Min Sci 2000;37:629-43. https://doi.org/10.1016/S1365-1609(00)00003-4.

[2] Funatsu T, Seto M, Shimada H, Matsui K, Kuruppu M. Combined effects of increasing temperature and confining pressure on the fracture toughness of clay bearing rocks. Int J Rock Mech Min Sci 2004;41:927-38. https://doi.org/10.1016/j.ijrmms.2004.02.008.

[3] Stöckhert F. Fracture mechanics applied to hydraulic fracturing in laboratory experiments. Ruhr University Bochum; 2015.

[4] Schmidt RA, Huddle CW. Effect of confining pressure on fracture toughness of Indiana limestone. Int J Rock Mech Min Sci Geomech 1977;14:289-93. https://doi. 
org/10.1016/0148-9062(77)90740-9.

[5] Kataoka M, Mahdavi E, Funatsu T, Takehara T, Obara Y, Fukui K, et al. Estimation of Mode i fracture toughness of rock by semi-circular bend test under confining pressure condition. Procedia Eng 2017;191:886-93. https://doi.org/10.1016/j.proeng.2017.05.258.

[6] Ulusay R. The ISRM suggested methods for rock characterization, testing and monitoring: 2007-2014; 2015.

[7] Wong LNY, Maruvanchery V, Liu G. Water effects on rock strength and stiffness degradation. Acta Geotech 2016;11:713-37. https://doi.org/10.1007/s11440015-0407-7.

[8] Zhou Z, Cai X, Cao W, Li X, Xiong C. Influence of water content on mechanical properties of rock in both saturation and drying processes. Rock Mech Rock Eng 2016;49:3009-25. https://doi.org/10.1007/s00603-016-0987-z.

[9] Chandler MR, Meredith PG, Brantut N, Crawford BR. Effect of temperature on the fracture toughness of anisotropic shale and other rocks. Geol Soc Lond, Spec Publ 2017:SP454.6. https://doi.org/10.1144/SP454.6.

[10] Chandler MR, Meredith PG, Brantut N, Crawford BR, Sciences E, Urc E. Fracture toughness anisotropy in shale. J Geophys Res Solid Earth 2016;121:1706-29. https://doi.org/10.1002/2015JB012756.

[11] Hua W, Dong S, Peng F, Li K, Wang Q. Experimental investigation on the effect of wetting-drying cycles on mixed mode fracture toughness of sandstone. Int J Rock Mech Min Sci 2017;93:242-9. https://doi.org/10.1016/j.ijrmms.2017.01.017.

[12] Huang SL, Speck RC, Wang Z. The temperature effect on swelling of shales under cyclic wetting and drying. Int J Rock Mech Min Sci 1995;32:227-36. https:// doi.org/10.1016/0148-9062(94)00044-4.

[13] Zhang C, Gamage RP, Perera MSA, Zhao J. Characteristics of clay-abundant shale formations: Use of CO2 for production enhancement. Energies 2017;10:1-27. https://doi.org/10.3390/en10111887.

[14] Stinco LP, Vaca BSP. Muerta formation: an example of shale heterogeneities controlling hydrocarbon accumulations. Proc Unconv Resour Technol Conf, 2. 2014. p. $1-15$.

[15] Zeller M, Reid SB, Eberli GP, Weger RJ, Massaferro JL. Sequence architecture and heterogeneities of a field - Scale Vaca Muerta analog (Neuquén Basin, Argentina) - From outcrop to synthetic seismic. Mar Pet Geol 2015;66:829-47. https://doi.org/10.1016/j.marpetgeo.2015.07.021.

[16] Shojae A. Porous rock fracture mechanics : with application to hydraulic fracturing, drilling and structural engineering. 1st ed. Cambridge (United Kingdom); 2017.

[17] Dutler N, Nejati M, Valley B, Amann F, Molinari G. On the link between fracture toughness, tensile strength, and fracture process zone in anisotropic rocks. Eng Fract Mech 2018;201:56-79. https://doi.org/10.1016/j.engfracmech.2018.08.017.

[18] Smith DJ, Ayatollahi MR, Pavier MJ. The role of T-stress in brittle fracture for linear elastic materials under mixed-mode loading. Fatigue Fract Eng Mater Struct 2001;24:137-50. https://doi.org/10.1046/j.1460-2695.2001.00377.x.

[19] Ayatollahi MR, Pavier MJ, Smith DJ. Mode I cracks subjected to large T-stresses. Int J Fract 2002;117:159-74.

[20] Williams ML. On the stress distribution at the base of a stationary crack. J Appl Mech 1957;24:109-14.

[21] Aliha MRM, Mahdavi E, Ayatollahi MR. The influence of specimen type on tensile fracture toughness of rock materials. Pure Appl Geophys 2016;174:1237-53. https://doi.org/10.1007/s00024-016-1458-x.

[22] Ayatollahi MR, Rashidi Moghaddam M, Berto F. A generalized strain energy density criterion for mixed mode fracture analysis in brittle and quasi-brittle materials. Theor Appl Fract Mech 2015. https://doi.org/10.1016/j.tafmec.2015.09.004.

[23] Kataoka M, Obara Y. Size effect in fracture toughness of sandstone. 13th ISRM Int Congr Rock Mech, 8555. 2015. p. 1-8.

[24] Hua W, Li Y, Dong S, Li N, Wang Q. T-stress for a centrally cracked Brazilian disk under confining pressure. Eng Fract Mech 2015;149:37-44. https://doi.org/10. 1016/j.engfracmech.2015.09.048.

[25] Hou C, Wang Z, Liang W, Yu H, Wang Z. Investigation of the effects of confining pressure on SIFs and T-stress for CCBD specimens using the XFEM and the interaction integral method. Eng Fract Mech 2017;178:279-300. https://doi.org/10.1016/j.engfracmech.2017.03.049.

[26] Tarokh A, Makhnenko RY, Fakhimi A, Labuz JF. Scaling of the fracture process zone in rock. Int J Fract 2017;204:191-204. https://doi.org/10.1007/s10704016-0172-0.

[27] Ayatollahi MR, Akbardoost J. Size effects on fracture toughness of quasi-brittle materials - a new approach. Eng Fract Mech 2012;92:89-100. https://doi.org/10. 1016/j.engfracmech.2012.06.005.

[28] Chao YJ, Liu S, Broviak BJ. Brittle fracture: Variation of fracture toughness with constraint and crack curving under mode I conditions. Exp Mech 2001;41:232-41. https://doi.org/10.1007/BF02323139.

[29] Liu S, Chao YJ. Variation of fracture toughness with constraint. Int J Fract 2003;124:113-7. https://doi.org/10.1023/B:FRAC.0000018230.97560.ae.

[30] Ayatollahi MR, Sedighiani K. Mode I fracture initiation in limestone by strain energy density criterion. Theor Appl Fract Mech 2012;57:14-8. https://doi.org/10. 1016/j.tafmec.2011.12.003.

[31] Akbardoost J, Ayatollahi MR, Aliha MRM, Pavier MJ, Smith DJ. Size-dependent fracture behavior of Guiting limestone under mixed mode loading. Int J Rock Mech Min Sci 2014;71:369-80. https://doi.org/10.1016/j.ijrmms.2014.07.019.

[32] Aliha MRM, Mahdavi E, Ayatollahi MR. Statistical analysis of rock fracture toughness data obtained from different chevron notched and straight cracked Mode I specimens. Rock Mech Rock Eng 2018;51:2095-114. https://doi.org/10.1007/s00603-018-1454-9.

[33] Aliha MRM, Sistaninia M, Smith DJ, Pavier MJ, Ayatollahi MR. Geometry effects and statistical analysis of mode I fracture in guiting limestone. Int J Rock Mech Min Sci 2012;51:128-35. https://doi.org/10.1016/j.ijrmms.2012.01.017.

[34] Ouchterlony F. Fracture toughness testing of rock with core based specimens. Eng Fract Mech 1990;35:351-66.

[35] Kuruppu MD, Obara Y, Ayatollahi MR, Chong KP, Funatsu T. ISRM-suggested method for determining the mode i static fracture toughness using semi-circular bend specimen. Rock Mech Rock Eng 2014;47:267-74. https://doi.org/10.1007/s00603-013-0422-7.

[36] Schmidt RA. Fracture-toughness testing of limestone. Exp Mech 1976;16:161-7. https://doi.org/10.1007/BF02327993.

[37] Celleri HM, Sánchez M, Otegui JL. Fracture behavior of transversely isotropic rocks with discrete weak interfaces. Int J Numer Anal Methods Geomech 2018;42:2161-76. https://doi.org/10.1002/nag.2849.

[38] ISRM. Suggested methods for determining the strength of rock materials in triaxial compression. Int J Rock Mech Min Sci Geomech Abstr 1978;15:47-51. https://doi.org/10.1016/0148-9062(78)91677-7.

[39] Vervoort A, Min KB, Konietzky H, Cho JW, Debecker B, Dinh QD, et al. Failure of transversely isotropic rock under Brazilian test conditions. Int J Rock Mech Min Sci 2014;70:343-52. https://doi.org/10.1016/j.ijrmms.2014.04.006.

[40] Li D, Wong LNY. The Brazilian disc test for rock mechanics applications: Review and new insights. Rock Mech Rock Eng 2013;46:269-87. https://doi.org/10. 1007/s00603-012-0257-7.

[41] Khanlari G, Rafiei B, Abdilor Y. An experimental investigation of the Brazilian tensile strength and failure patterns of laminated sandstones. Rock Mech Rock Eng 2014;48:843-52. https://doi.org/10.1007/s00603-014-0576-y.

[42] Zhou Z, Cai X, Ma D, Cao W, Chen L, Zhou J. Effects of water content on fracture and mechanical behavior of sandstone with a low clay mineral content. Eng Fract Mech 2018;193:47-65. https://doi.org/10.1016/j.engfracmech.2018.02.028.

[43] Guha Roy D, Singh TN, Kodikara J, Das R. Effect of water saturation on the fracture and mechanical properties of sedimentary rocks. Rock Mech Rock Eng 2017;50:2585-600. https://doi.org/10.1007/s00603-017-1253-8.

[44] Van Eeckhout EM. The mechanisms of strength reduction due to moisture in coal mine shales. Int J Rock Mech Min Sci Geomech 1976;13:61-7. https://doi.org/ 10.1016/0148-9062(76)90705-1.

[45] Antinao Fuentealba FJ, Bianchi GL, Sánchez CA, Ramos R. Fracture toughness experiments in shale rocks, effect of fluid chemestry on KIc. 10th hydrocarb explor dev congr, Mendoza, Argentina. 2018. p. 1-17.

[46] Brown K, Baratta F. Chevron-notch fracture test experience: metals and non-metals. STP1172. West Conshohocken (PA): ASTM International; 1992. https:// doi.org/10.1520/STP1172-EB.

[47] Ewy RT. Shale swelling/shrinkage and water content change due to imposed suction and due to direct brine contact. Acta Geotech 2014;9:869-86. https://doi. 
org/10.1007/s11440-013-0297-5.

[48] Atkinson BK. Fracture mechanics of rock. Academic Press; 1987. https://doi.org/10.1016/C2009-0-21691-6.

[49] Nara Y, Hiroyoshi N, Yoneda T, Kaneko K, Morimoto K, Hiroyoshi N, et al. Influence of relative humidity on fracture toughness of rock: Implications for subcritical crack growth. Int J Solids Struct 2012;49:2471-81. https://doi.org/10.1016/j.ijsolstr.2012.05.009.

[50] Wilson MJ, Wilson L. Clay mineralogy and shale instability: an alternative conceptual analysis. Clay Miner 2014;49:127-45. https://doi.org/10.1180/claymin. 2014.049.2.01.

[51] Grgic D, Giraud A. The influence of different fluids on the static fatigue of a porous rock: Poro-mechanical coupling versus chemical effects. Mech Mater 2014;71:34-51. https://doi.org/10.1016/j.mechmat.2013.06.011.

[52] Jeong H Sik, Kang S Seung, Obara Y. Influence of surrounding environments and strain rates on the strength of rocks subjected to uniaxial compression. Int J Rock Mech Min Sci 2007;44:321-31. https://doi.org/10.1016/j.ijrmms.2006.07.009.

[53] Taylor D. The theory of critical distances. Eng Fract Mech 2008;75:1696-705. https://doi.org/10.1016/j.engfracmech.2007.04.007.

[54] Bazant ZP, Rajapakse Y. Fracture Scaling. Springer; 1999.

[55] Ayatollahi MR, Aliha MRM. Wide range data for crack tip parameters in two disc-type specimens under mixed mode loading. Comput Mater Sci 2007;38:660-70. https://doi.org/10.1016/j.commatsci.2006.04.008.

[56] Hua W, Xu J, Dong S, Song J, Wang Q. Effect of confining pressure on stress intensity factors for cracked brazilian disk. Int J Appl Mech 2015;07:1550051. https://doi.org/10.1142/s1758825115500519.

[57] Serebrinsky S, Morris W, Araujo A, Belmonte J, Márquez A. A method for the determination of fracture toughness in core samples considering pressure on the crack faces. $10^{\circ}$ Congr Explor. y Desarro. Hidrocarburos, Mendoza, Argentina. 2018. p. 47-56.

[58] Carpinteri A, Carpentieri A. Stress intensity factors for straight-fronted edge cracks in round bars. Eng Fract Mech 1992;42:1035-40. https://doi.org/10.1016/ 0013-7944(92)90142-2.

[59] Guo H, Aziz NI, Schmidt LC. Rock fracture-toughness determination by the Brazilian test. Eng Geol 1993;33:177-88. https://doi.org/10.1016/0013-7952(93) 90056-I.

[60] Backers T. Fracture toughness determination and micromechanics of rock under Mode I and Mode II loading. Germany: University of Potsdam; 2004.

[61] Chavez A., Otegui J., Sánchez M, Morris W, Bianchi G. Field and experimental brittleness (toughness) determination of Vaca Muerta Shale. ARMA; 2015.

[62] Massaro Sosa A. Estudio Geomecánico Regional de la Formación Vaca Muerta y su Aplicación a los Reservorios No Convencionales del tipo Shale oil/gas. Instituto Tecnológico de Buenos Aires; 2019.

[63] Rybacki E, Meier T, Dresen G. What controls the mechanical properties of shale rocks? - Part II: Brittleness. J Pet Sci Eng 2016;144:39-58. https://doi.org/10. 1016/j.petrol.2016.02.022.

[64] Akbardoost J. Size and crack length effects on fracture toughness of polycrystalline graphite. Eng Solid Mech 2014;2:183-92. https://doi.org/10.5267/j.esm. 2014.4.005.

[65] Tutluoglu L, Keles C. Mode I fracture toughness determination with straight notched disk bending method. Int J Rock Mech Min Sci 2011;48:1248-61. https:// doi.org/10.1016/j.ijrmms.2011.09.019.

[66] Ayatollahi MR, Mahdavi E, Alborzi MJ, Obara Y. Stress intensity factors of semi-circular bend specimens with straight-through and chevron notches. Rock Mech Rock Eng 2016;49:1161-72. https://doi.org/10.1007/s00603-015-0830-y.

[67] Wei MD, Dai F, Xu NW, Liu Y, Zhao T. A novel chevron notched short rod bend method for measuring the mode I fracture toughness of rocks. Eng Fract Mech 2018;190:1-15. https://doi.org/10.1016/j.engfracmech.2017.11.041.

[68] Nie Y, Zhang G, Xing Y, Li S. Influence of water-oil saturation on the fracture process zone: a modified Dugdale-Barenblatt model. Energies 2018;11:2882. https://doi.org/10.3390/en11112882.

[69] Schmitt L, Forsans T, Santarelli FJ. Shale testing and capillary phenomena. Int J Rock Mech Min Sci 1994;31:411-27. https://doi.org/10.1016/0148-9062(94) 90145-7.

[70] Ghamgosar M, Erarslan N, Williams DJ. Experimental investigation of fracture process zone in rocks damaged under cyclic loadings. Exp Mech 2017;57:97-113. https://doi.org/10.1007/s11340-016-0216-4. 